\title{
The Role of Emotional Intelligence in Organizational Performance
}

\author{
Heléna Krén ${ }^{1 *}$, Beatrix Séllei ${ }^{1}$ \\ ${ }^{1}$ Department of Ergonomics and Psychology, Faculty of Economics and Social Sciences, Budapest University of Technology and \\ Economics, H-1117 Budapest, P. O. B. 91, Hungary \\ * Corresponding author, e-mail: helus0320@gmail.com
}

Received: 07 March 2020, Accepted: 11 May 2020, Published online: 25 November 2020

\begin{abstract}
Emotional intelligence may affect organizational performance, and the aim of our research was to examine whether this statement can be proven in the case of financially successful organizations or not. Information about leaders has been derived from online surveys with Genos El and also from interviews, and we gathered data about organizational success from the national TAX system. Leaders usually determine group and organizational effectiveness, so we analyzed data from 22 leaders working in successful Hungarian companies. According to our results, some emotional competencies correlate with performance. In this case self-awareness, awareness of others and self-management seemed to affect organizational performance. In our regression analysis, self-awareness seemed to be a predictor variable of performance. The relationship between emotional intelligence and performance should be examined further by expanding on the analysis of other performance indicators and leadership styles.
\end{abstract}

\section{Keywords}

emotional intelligence, leadership, performance, emotional competencies, effectiveness, Genos

\section{Introduction}

\subsection{Literature review of emotional intelligence}

Emotional intelligence is a commonly used term but actually a hardly defined psychological concept. Therefore, there comes a question: what does emotional intelligence universally mean?

As an umbrella term emotional intelligence accounts for emotional and social problem solving. Depending from the theories on which researches are built, usually we can differentiate 4 types of emotional intelligence models: ability based, trait based and two main mixed models. Mayer et al. created the fundamental ability model of emotional intelligence on four levels (Mayer et al., 2000). The basic level is connected to the ability of perceiving emotions. The second level is concerned with the ability of assimilating incoming information and using emotions for mental processes. The third ability level is understanding and reasoning with emotions. On the fourth level of the model we are able to manage and regulate our own and other's emotions (Mayer et al., 2000).

The trait model regards emotional intelligence as "a personality trait encompassing a constellation of emotion-related dispositions and self-perceptions" (LopezZafra et al., 2012:p.99). The model of Petrides and Furnham is an alternative model of emotional intelligence and part of the second generation of EI models because it was built on the previous model and operates with similar personal qualities (Cherniss, 2010b). Well-being, sociability, self-control and emotionality refer to the four components of the trait EI model (Pérez et al., 2005).

The model of Bar-On (2006) and the model of Goleman and Boyatzis count as the mixed models. They are mixed in a way that they operate with social behavior, traits and competencies connected to emotions (Mandell and Pherwani, 2003). Bar-On (2006) conceptualized emotional intelligence in association with social and emotional competencies. According Bar-On's theory of social and emotional intelligence, this is a set of abilities which determinate how effectively we behave. Emotional components are intrapersonal and interpersonal abilities, stress-management, adaptation and general mood (Bar-On, 2006). Another mixed model was built on the theory of social and emotional competencies which are crucial from the aspect of workplace performance (Cherniss, 2010b). Boyatzis (2009) considered emotional intelligence as a competency - embodying the ability of perceiving, understanding and using emotional information - which guarantees outstanding performance in life. Thereof his conceptualization Goleman (2004) describes 
emotional intelligence as ability-based competency, which can be learned or even developed and contributes to high workplace performance (Cherniss, 2010b).

The previous model is also ability-based, but one of the current theoretical approaches is from the model of the Swinburne University Emotional Intelligence Test (SUEIT) developed Genos EI, devised by Palmer et al. (2009). This model was built on Gignac's definition of emotional intelligence. Gignac extended the conceptual line of emotional intelligence, opening the scope from closer, interpersonal relationships to the wider environment. Gignac defined this construct as "an ability to purposively adapt, shape, and select environments through the use of emotionally relevant processes" (Gignac, 2010:p.131). These abilities are measurable by the competencies of the Genos EI model - self-awareness, awareness of others, authenticity, emotional reasoning, self-management and inspiring performance - and refer to the most important workplace soft skills (Palmer and Gignac, in press).

\subsection{The role of EI in leadership and organizations}

Many researchers believe emotional intelligence has importance and high effect in life, especially when it comes to leading people. Emotional intelligence is usually analyzed in connection with interpersonal relations, such as leader-employee relationships. Leading is usually interpreted as an influencing process through which employees can be motivated, goals can be set out and high performance can be provided (Fehér, 2010). According the idea of Goleman et al. (2003) emotional influence is an essential part of leadership and leaders are the main figures who manage the mood and emotions of a community.

On this conception was built the idea of resonant leadership, which describes how leaders can be successful using effectively their own and their employees' emotions. Leaders' reactions determine employees' behavior. Emotional reactions can lead to emotional norms inside the group. In this sense leaders' emotional reactions are crucial from the point of team and organizational success. According to resonant leadership theory, leaders have to create an emotionally resonant atmosphere where employees can securely and successfully use their skills. Leaders can use their own emotions to create such an atmosphere, just by the way they behave or by sharing emotionally important experiences or feelings. High emotionally intelligent leaders can build reciprocal trust and a comfortable environment, share knowledge, involve employees in decision-making, encourage teamwork, strengthen engagement and guarantee organizational performance with high effectiveness (Goleman et al., 2003). From this point of view, leaders and their emotional behavior play an important role in everyday work because leading is an emotionally loaded process. That is why emotions and emotionally intelligent behavior can affect success through relationship with employees (George, 2000).

Considering the fact that emotional intelligence is an interrelationship phenomenon, Ashkanasy (2003) defined organizational emotional intelligence in five steps, starting from the individual levels to the organizational level. According to his conception, emotions appear first on a within-person level, then between persons in a form of emotional intelligence. Before we catch the effect of emotions on the organizational level, we should take into consideration interpersonal interactions where emotional exchanges take place and on the fourth level leader-member emotional exchange which leads to emotionally intelligent groups (Ashkanasy, 2003). Groups are characterized by group mood, which is usually determined by members' emotional characteristics. This mood can be shaped by emotional contagion, modelling or manipulation, but most of all by the leaders' behavior, and their expressed feelings and emotions (Ashkanasy, 2003). Ashkanasy and Humphrey (2011) emphasize the fact that leaders are capable of enhancing performance through developing positive effects and moods in group members. This is connected to Goleman's resonant leadership theory (Goleman et al., 2003), because both conceptions are built on workplace atmosphere and the role of leaders in building it up for high performance.

Goleman et al. (2003) found that self-awareness and empathy contribute to organizational success, but it is possible just in case emotionally intelligent behavior, which supports group norms, is accepted and is vivid in the organization. The most emotionally intelligent members who can express and verbalize emotions help others to recognize emotions and so develop emotional awareness in the whole group. Usually the leader is also the group's emotional leader, who transmits the emotional supporting norms (Goleman et al., 2003). Because of this role, leaders should be aware of their own emotions, and on an interpersonal level they should regulate emotions and behave with emotionally intelligence for having an effect on the whole group and guaranteeing organizational effectiveness (Ashkanasy and Humphrey, 2011).

\subsection{Emotional intelligence and performance}

Emotional intelligence is one of the most important parts of competitiveness not only in private life but also in organizations. The question whether emotional intelligence or 
cognitive intelligence can predict effectiveness has not been precisely answered yet.

Some results bring into question the correlation between emotional intelligence and performance (Cherniss, 2010a; Goleman, 2004). Feyerherm and Rice (2002) could partially confirm that emotions correlate with group performance. While understanding emotions and managing them correlated with group performance, no other emotional component was correlated to productivity or increased performance. Neither Day and Carroll(2004) could confirm the fact that emotional intelligence as a whole concept is correlated with performance. Although Day and Carroll (2004) found some supporting evidence in a lower level - between emotional perception and performance in a decision-making task -, Rapisarda (2002), as with the previously mentioned theory makers, did not find any correlation between group emotional intelligence and group performance. Although Langhorn (2004) could not significantly support the correlation between profit and leaders' emotional intelligence, numerical data showed the difference between leaders of high performance and low performance restaurants. Performance evaluation results supported the positive relation between emotional intelligence and leaders' performance with a 21 percent explained variance. Langhorn found that emotional awareness is the best predictor of leader performance (Langhorn, 2004). Also, Wong and Law (2002) analyzed the emotional intelligence of leaders and emphasized that leaders should be aware of emotions, understand them and should be able to regulate emotions for successful cooperation with others. Leaders can be deem good if they can solve complex social problems in organization. Wong and Law's results strengthened the relation of emotional intelligence and workplace performance. They found that this relationship is moderated by emotional labor. According this employees' emotional intelligence and emotionally influenced behavior affect their work performance (Wong and Law, 2002).

Against previously mentioned results, O'Boyle et al. (2011) found a low significant correlation between emotional intelligence and work performance. They detected that cognitive abilities and conscientiousness explain the biggest part of the total variance with 86.3 percent oppositely emotional intelligence which explains 13.6 percent of the variance. Emotional intelligence playing an important role in performance is partially supported, but being the one and only manipulator of performance is not proven because of possible moderator variables (O'Boyle et al., 2011). Many researchers query the role of emotional intelligence in performance (Day and Carroll, 2004; Feyerherm and Rice, 2002; O'Boyle et al., 2011; Rapisarda, 2002) although in many cases they can partially support the correlation between the two variables.

Despite the skeptical approaches, there are several supporting research papers (Langhorn, 2004; Sy et al., 2006; Wong and Law, 2002) in which a leader's emotional intelligence and its effect on organizations and organizational performance are supported by the whole concept of emotional intelligence or emotional dimensions.

As an alternative stance, Coté and Miners (2006) hypothesized that the relation between emotional intelligence and performance is moderated by cognitive intelligence. This means the lower cognitive intelligence, the stronger the correlation between the other two variables. Cognitive intelligence alone is not able to explain differences in performance. Emotional intelligence may complete the effect of cognitive abilities or compensate their dysfunctions. Emotional intelligence can enhance the performance of people with low cognitive abilities. This supports the presumption that emotional intelligence can compensate cognitive intelligence and affect performance (Coté and Miners, 2006).

\subsection{Research question - hypotheses}

As we see from the literature, emotional intelligence plays an important role in leadership and forms a part of performance, but the nature of the relationship between these three concepts is not yet clear, as is also the case with the definition of emotional intelligence itself. Because workplace related literature usually operates with competency-based measurements, we also selected a competency-based new survey, Social and Emotional Competence Survey (SECS) (Palmer and Gignac, in press) to define and measure a leader's emotional intelligence.

We share the opinion of O'Boyle et al. (2011) that emotional intelligence can explain some variance in performance, thus emotional dimensions could give us a deeper understanding and make clearer the role of emotions in performance. Leaders are the main figures in organizations. Their emotionally intelligent behavior is critical from the point of organizational effectiveness. That is why their emotional intelligence level and their emotionally intelligent behavior need to be examined. Many researches were built on the relevance of self-awareness and emotional management. Self-awareness, empathy and emotional regulation can help leaders by creating a positive, comfortable and productive atmosphere for employees. There is supporting evidence in the literature (Cherniss, 2001; Coté and 
Miners, 2006; Goleman, 2001, 2004; Goleman et al., 2003; Sy et al., 2006; Wong and Law, 2002). Thus, we think this evidence will appear in connection with Hungarian leaders. According to this, our hypotheses are:

1. Organizational performance defining factors are self-awareness, self-management and awareness of others.

2. Leaders of the most successful organizations have higher levels of emotional awareness.

3. Higher self-management of leaders provides higher organizational performance.

\section{Method}

\subsection{Participants and procedure}

This research was the basis of a master thesis. Recruiting participants started in January 2019. 34 Hungarian leaders participated in the research, 16 men and 18 women. The ages of the participants ranged from 30 to 58 with a mean of 42 ( $\mathrm{SD}=8.12)$. They are not working on the same levels of organizations. 19 senior executives, 8 mid-level managers and 6 junior managers who work on the third level of organizations counting from the top were part of our sample. They have worked in their current positions averagely for 6.75 years $(\mathrm{SD}=7.2)$. Their leadership experience in years ranged from 0.5 to 34 with an average of 11.4 years $(\mathrm{SD}=8.66)$. The average number of subordinates was $8.15(\mathrm{SD}=5.84)$.

At the starting point verbal and also written information was delivered to the participants. After informing them, they received an online link to the survey, which we used for gathering data. The next step was an interview and feedback about results where we asked for permission to use their results as research material. Lastly, data of annual financial reports downloaded from the website of the Ministry of Justice were gathered. From these reports we used the net of annual turnover and the number of persons employed. The gathering of online and personal data ended in April 2019.

The aim of this research was to examine successful organizations so net of annual turnover was taken into consideration as an important aspect of successful performance. The results of leaders whose organizational performance showed annual turnover or no decrease were analyzed. Then, those leaders, whose income did not fall between 2016 and 2017 because some organization were established in 2016, took part in our research.

Seven leaders did not answer our request and did not give interviews. In the case of seven organizations, there were no available income data, and two did not publish financial reports. Five entrepreneurs did not give information about their own businesses so their financial reports could not be discovered. All together 22 leaders answered the survey and our interview questions. 10 men and 12 women between 30 and 58 years old formed our sample thanks to the convenience sampling method among the partners of a Hungarian consultant company.

Participation in the research was voluntary and participants did not receive any reward.

\subsection{Measurements}

Leaders completed an online survey measuring emotionally intelligent behavior in the workplace and were interviewed.

Social and Emotional Competence Survey (SECS) (Palmer and Gignac, in press) developed by Ben Palmer and Con Stough was used in our research. Two versions of this survey exist, one for leaders and one for everyone in workplaces. We selected for research the leadership version which allows the description of socially and emotionally competent leadership behaviors from the perspective of six competencies. SECS Leadership 180 Survey is a multi-rater assessment because this 42-item questionnaire is based on self and multi-rater evaluations. Evaluations should be made on a 5-point Likert scale from "significantly less than others" to "significantly more than others". This survey is unique because it enables the measurement of how important items are also on a 5-point Likert scale. Every competency is measured by seven items and in each case qualitative feedback also can be appended (Palmer and Gignac, in press).

The fitness of measurement was proven by factorial validity and internal consistency reliability in all six dimensions of the survey. Self-rater-scales' reliability were estimated via Cronbach $\alpha(\alpha=0.79$ to 0.89$)$. In observer ratings the same reliability is noticeable ( $\alpha=0.85$ to 0.91 ) (Palmer and Gignac, in press). The translated measurement showed a similar internal consistency reliability with 0.916 in self-assessment and 0.977 in rater assessment results.

The six competencies are:

- Self-Awareness: ability which helps to realize how you feel and the impact of feelings on decisions, behavior and performance,

- Awareness of Others: ability that makes us capable to perceive, understand and acknowledge the feeling of others,

- Authenticity: ability to openly and effectively express feelings and thoughts, to honor commitment and encourage it in others, 
- Emotional Reasoning: ability of using information from feelings in decision-making,

- Self-Management: means being able to manage one's mood and emotions, time and behavior; and to improve oneself and

- Inspiring Performance: ability which is manifested in problem solving, promoting, recognizing and supporting others to provide high performance.

Our interview questions are related to demography, coordinated teams and leadership tasks. While editing the interview structure we considered topics which are usually connected to emotional intelligence in leadership or to its effect.

\section{Results}

\subsection{Descriptive statistics}

Considering performance criterion results from 22 participants were analyzed. 7 senior executives, 8 mid-level managers and 6 junior managers; from these 8 self-employed workers and 14 employees took part in our research. One leader filled out the survey, but was not interviewed. In spite of this the assessment results and financial data are part of the sample because of being one of the partners of the consultant company. The participants' age ranged from 30 to 58 with a mean of 40.67 (SD = 7.87). They have been working in their current positions averagely for 5.36 years $(\mathrm{SD}=6.41)$. Their leadership experience measured in years ranged from 0.5 to 34 with an average of 9.74 years $(\mathrm{SD}=7.88)$. The average number of subordinates was $8.24(\mathrm{SD}=6.25)$.

Participating companies' income data with descriptive statistics are shown in Table 1. Every company had income in 2017 so this year was statistically analyzed. Annual turnover did not show a normal distribution $(W=0.469 ; p<0.001)$, so we used log-transformation. Transformed variable did not differ from normal distribution $(W=0.957 ; p=0.322$ ).

Detailed descriptive statistics of SECS and its factors are in Table 2 and Table 3. Leaders think they do best in Emotional reasoning while their raters say leaders most of all inspire performance. Leaders think they do not really manage themselves successfully, while they are not much

Table 1 Net of annual turnover in 2016 and 2017

\begin{tabular}{lcc}
\hline & $\begin{array}{c}\text { Net of annual turnover } \\
2016(\mathrm{HUF}) \\
(\mathrm{N}=22)\end{array}$ & $\begin{array}{c}\text { Net of annual turnover } \\
2017 \text { (HUF) } \\
(\mathrm{N}=22)\end{array}$ \\
\hline Mean & 19206663090 & 23532787050 \\
$\mathrm{SD}$ & 41740385750 & 50028917750 \\
Minimum & 0 & 535000 \\
Maximum & 142780579000 & 117478514000 \\
\hline
\end{tabular}

Table 2 Results of emotional demonstration level based on SECS and its dimensions according leaders

\begin{tabular}{lccccc}
\hline & N & Mean & SD & Min. & Max. \\
\hline SUM_EI & 22 & 3.99 & 0.43 & 3.12 & 4.67 \\
SA_d & 22 & 3.88 & 0.55 & 2.7 & 4.7 \\
AO_d & 22 & 3.98 & 0.43 & 3 & 4.7 \\
A_d & 22 & 3.99 & 0.57 & 2.9 & 4.9 \\
SM_d & 22 & 3.81 & 0.51 & 2.9 & 4.7 \\
ER_d & 22 & 4.19 & 0.46 & 3.1 & 4.9 \\
IP_d & 22 & 4.04 & 0.59 & 2.7 & 4.7 \\
\hline
\end{tabular}

Table 3 Results of emotional demonstration level based on SECS and its dimensions according raters

\begin{tabular}{lccccc}
\hline & N & Mean & SD & Min. & Max. \\
\hline SUM_EI & 22 & 4.02 & 0.44 & 2.79 & 4.68 \\
SA_d & 22 & 3.95 & 0.48 & 2.8 & 4.7 \\
AO_d & 22 & 3.89 & 0.53 & 2.5 & 4.6 \\
A_d & 22 & 4.06 & 0.48 & 2.8 & 4.7 \\
SM_d & 22 & 4.06 & 0.42 & 2.7 & 4.8 \\
ER_d & 22 & 4.07 & 0.45 & 3.1 & 4.8 \\
IP_d & 22 & 4.1 & 0.53 & 2.8 & 4.9 \\
\hline
\end{tabular}

Note: SUM_EI=total emotional intelligence score,

SA_d= demonstrated Self-awareness,

AO_d=demonstrated Awareness of others,

A_d $=$ demonstrated Authenticity,

SM_d= demonstrated Self-management,

ER_d= demonstrated Emotional reasoning,

IP_d $=$ demonstrated Inspiring performance.

aware of others, considering the minimum and maximum of means according raters.

\subsection{Hypothesis testing}

Testing the first hypothesis linear regression was used to see whether Self-awareness, Self-management and Awareness of others predict successful performance or not. Self-awareness $(\beta=1.551 ; p<0.016)$ and Inspiring performance $(\beta=-1.279 ; p<0.029)$ from leaders' assessments were the best predictors when analyzing the whole sample $\left(F(2,19)=4.161 ; p=0.032 ; R^{2}=0.305\right)$.

We could identify income defining factors only in a subgroup of leaders, who work in organizations as employees. One of the significant models $(F(4,9)=4.845 ; p=0.023$, $\left.R^{2}=0.683\right)$ shows that Awareness of others $(\beta=-2.582$; $p=0.003)$ and Authenticity $(\beta=1.512 ; p=0.008)$ influence performance the most based on leaders' assessment and Inspiring performance $(\beta=2.068 ; p=0.031)$ is also an influencing factor of performance according raters.

Linear regression in subgroups showed in another model that Self-management ( $\beta=-2.314 ; p=0.037$ ) and Inspiring 
performance $(\beta=2.257 ; p=0.018)$ according raters and Awareness of others $(\beta=-3.021 ; p=0.002)$ according to the leaders' evaluation are influencing income the most in the case of employed leaders $(F(5,8)=4.977 ; p=0.023$; $R^{2}=0.757$ ).

Analyzing total emotional intelligence, there were no correlations either between total emotional intelligence score by leaders and income $(r=0.102 ; p=0.651)$ or between total emotional intelligence score by raters and income $(r=0.157 ; p=0.487)$. Income showed correlation only with leadership level $(r=0.527 ; p=0.014)$ and giving feedback to the principal $(r=0.470 ; p=0.032)$.

The relationship between performance and Self-awareness was analyzed to see whether the leaders of the most successful organizations have higher levels of emotional awareness or not and so verify the second hypothesis. There were no correlations between turnover and Self-awareness either in leaders' self-assessment $(r=0.315 ; p=0.154)$ or in raters' assessment $(r=0.061 ; p=0.788)$. In subgroups we could not find any significant effect of emotional dimensions.

Based on the third hypothesis the correlation between performance and Self-management was analyzed to explore a positive relationship. Testing the total emotional intelligent scores, neither in the leadership group $(r=0.204$; $p=0.361)$ nor in a rater group $(r=0.157 ; p=0.486)$ were any significant relations found. But in the group of midlevel managers, we could confirm the correlation with significant results between self-assessed Self-management and income $(r=0.736 ; p=0.037)$. This correlation could be strengthened separately among men $(r=-0.656 ; p=0.039)$ and women $(r=0.693 ; p=0.012)$ considering self-assessment scores and their relation to Self-management.

\section{Discussion}

In our research, we analyzed the emotional intelligence of leaders working in successfully performing organizations and the contribution of their emotional intelligence to performance. We examined which emotional dimensions influence income the most and we formulated three hypotheses in connection with organizational performance defining factors.

Our first and the most important question was how emotional intelligence affects organizational performance. Coté and Miners (2006) and O'Boyle et al. (2011) confirmed that emotional intelligence and performance are correlated in some aspects. We shared their opinion and expanded their assumption with Goleman's results (2004). Goleman (2004) proved that knowing our own emotions, regulating them, the awareness of others and empathy toward them help leaders to build a positive, inspiring and motivating atmosphere for subordinates.

Based on these preliminaries, we hypothesized that organizational performance will be affected by Self-awareness, Self-management and Awareness of others. Our results slightly confirmed the relation between these variables. On analyzing the whole sample, linear regression showed that Self-awareness affects performance in a positive way. In this case Inspiring performance also appeared to be a relevant predictor of performance. In the subgroup of employed leaders, we found a negative relationship between performance, Self-management and Awareness of others.

The connection between emotional intelligence and transformational leadership style is proven by Mandell and Pherwani (2003) and Lopez-Zafra et al. (2012). They found that transformational leadership can predict emotional intelligence. Inspiring performance is one of its important components, so this could be the reason why Inspiring performance using SECS also seemed to be relevant. Bar-On (1997) emphasized that transformational leaders with high emotional intelligence are capable of outstanding performance. Bass (1990) also mentioned that leaders should possess more types of intelligence, thereunder with emotional intelligence to successfully motivate employees. These results could explain why Inspiring performance came out to be an influencing predictor of performance.

Negative relationship in the case of Self-management and Awareness of others can be related to emotional labor. Wong and Law (2002) proved that the relation between emotional intelligence and performance can be moderated by emotional labor. In connection with interpersonal relationships Ashkanasy (2003) also emphasized how the required but not authentically emotional behavior affects organizational effectiveness. Goldberg and Grandey (2007) found that modified emotional reactions negatively affect performance in customer service.

Our second and third hypotheses were formulated based on Goleman et al. (2003) resonant leadership theory. According to resonant leadership, emotionally intelligent leaders are able to create a resonant atmosphere by harmonizing their own emotions with environmental actions. Self-awareness and Self-management should play a huge role in this harmonization. Next to Goleman et al. (2003), Cherniss (2001) also emphasized the importance of emotional self-awareness and self-management in group functioning. Taking into consideration that leaders are norms defining individuals (Goleman et al., 2003), we suggested 
that leaders' emotional characteristics will be related to performance. Langhorn (2004) also confirmed the relationship between self-awareness and performance. Finally, some research material can prove the connection between self-management and performance too (Cherniss, 2010a; Wong and Law, 2002).

Testing our hypotheses, we could not confirm a significant correlation between Self-awareness and income. But to strengthen the third hypothesis, we could affirm a positive correlation between Self-management and income among mid-level managers. This relationship could be confirmed among men and women as well. Results showed a negative correlation in the case of men, but a positive one in the case of women. Negative correlation by men may refer to a behavioral phenomenon among men. The more they regulate their emotions the less effective they are at work. While among women, the more they regulate their emotional reactions the better they can perform.

Self-awareness results can be explained by supposing a common contribution of leader and teammates to organizational performance. Although Goleman et al. (2003) emphasized the role of leaders, probably the interrelationship between leader and subordinates and emotionally intelligent behavior in this context has a higher effect on performance. From this aspect, leaders and their self-awareness are not enough because the reaction of the group can also modify the performance or the outcome of the cooperation (Ashkanasy, 2003). According to these ideas, leaders are not able to define performance, therefore our second hypothesis could not have been affirmed anyway.

Opposite to the previous Self-awareness results, Selfmanagement results strengthen the effect of leaders in influencing performance. We found reassurance for the third hypothesis among mid-level managers and also among men and women. Goleman et al. (2003) stated that in many cases mid-level managers direct people and business, so they need to be aware of their emotional competencies and the effect of emotional functioning in organizations, which can be detected at their level. The difference between the genders in emotional intelligence is not new. Mayer et al. (1999) and Mandell and Pherwani (2003) found difference in emotional intelligence scores of men and women, with higher scores for women. Mandell and Pherwani (2003) also formulated that women may regulate better emotions. Our results are consonant with Mandell and Pherwani's. Based on our data analysis, we can say that the emotion regulation of women contributes to higher performance, while this could not be affirmed in our sample among men.

\section{Summary}

Emotional intelligence is not a clearly defined concept which is proven by the variance of models of emotional intelligence (Bar-On, 2006; Gignac, 2010; Goleman, 2004; Mayer et al., 2000; Pérez et al., 2005; Salovey and Mayer, 1990). The relationship between emotional intelligence and performance is as unstable as the definition of this psychological concept.

The "Big Idea" of Cherniss (2010a) gave the impulse for researching and understanding the contribution of emotional and cognitive intelligence to performance. Some researchers strengthened the relation (Cherniss, 2010a; Goleman, 2004; Langhorn, 2004; Sy et al., 2006; Wong and Law, 2002); while some found doubtful results (Day and Carroll, 2004; Feyerherm and Rice, 2002; O'Boyle et al., 2011; Rapisarda, 2002). We state that emotional intelligence is connected to performance in some ways and we share the opinion of Coté and Miners (2006) that there should be moderating variables in this connection.

Data of 22 leaders whose organizations met performance criteria - according to which organizations should keep income level or secure an increasing turnover - were analyzed. Results showed that emotional intelligence is not able to predict organizational performance as a whole concept. But emotional self-awareness, self-management and awareness of others seemed to be related to performance. Furthermore, self-awareness predicts performance based on our regression analysis. We can draw the conclusion that understanding emotions and developing emotion regulation can help achieve occupational goals and increase workplace performance. These effects could also have been confirmed in subgroups.

In further research some other variables should be analyzed for measuring performance like in the research of Coté and Miners (2006) in case of group performance. As O'Boyle et al. (2011) and Coté with Miners (2006) hypothesized there can be moderating variables in the relationship between emotional intelligence and performance, so we think that some other variables, like transformational leadership style could moderate this relation. As a result of this, emotional intelligence should be examined in association with leadership styles and applied performance indicators to make clearer the relationship of emotional intelligence to performance. 


\section{References}

Ashkanasy, N. M. (2003) "Emotions in Organizations: A Multi-level Pespective", In: Dansereau, F., Yammarino, F. J. (eds.) Multi-Level Issues in Organizational Behavior and Strategy, Emerald Group Publishing Limited, Bingley, UK, pp. 9-54. https://doi.org/10.1016/S1475-9144(03)02002-2

Ashkanasy, N. M., Humphrey, R. H. (2011) "Current Emotion Research in Organizational Behavior", Emotion Review, 3(2), pp. 214-224. https://doi.org/10.1177/1754073910391684

Bar-On, R. (1997) "The Emotional Quotient Inventory (EQ-i): A test of emotional intelligence", Multi-Health Systems, Toronto, Canada.

Bar-On, R. (2006) "The Bar-On model of emotional-social intelligence (ESI)", Psicothema, 18(1), pp. 13-25.

Bass, B. M. (1990) "From transactional to transformational leadership: Learning to share the vision", Organizational Dynamics, 18(3), pp. 19-31.

https://doi.org/10.1016/0090-2616(90)90061-S

Boyatzis, R. E. (2009) "Competencies as a behavioral approach to emotional intelligence", Journal of Management Development, 28(9), pp. 749-770.

https://doi.org/10.1108/02621710910987647

Cherniss, C. (2001) "Emotional Intelligence and Organizational effectiveness", In: Cherniss, C., Goleman, D. (eds.) The Emotionally Intelligent Workplace: How to select for, measure, and improve emotional intelligence in individuals, groups and organizations, Jossey-Bass, San Francisco, CA, USA.

Cherniss, C. (2010a) "Emotional Intelligence: New Insights and Further Clarifications", Industrial and Organizational Psychology, 3(2), pp. $183-191$. https://doi.org/10.1111/j.1754-9434.2010.01222.x

Cherniss, C. (2010b) "Emotional Intelligence: Toward Clarification of a Concept", Industrial and Organizational Psychology, 3(2), pp. 110-126.

https://doi.org/10.1111/j.1754-9434.2010.01231.x

Coté, S., Miners, C. T. H. (2006) "Emotional Intelligence, Cognitive Intelligence, and Job Performance", Administrative Science Quarterly, 51(1), pp. 1-28. https://oi.org/10.2189/asqu.51.1.1

Day, A. L., Carroll, S. A. (2004) "Using an ability-based measure of emotional intelligence to predict individual performance, group performance, and group citizenship behaviours", Personality and Individual Differences, 36(6), pp. 1443-1458. https://doi.org/10.1016/S0191-8869(03)00240-X

Fehér, J. (2010) "Kortárs személyes vezetési elméletek: A transzformatív felfogás szerepe és jellemzői I. rész" (Contemporary personal leadership theories: The role and characteristics of transformative perception Part I), Vezetéstudomány - Budapest Management Review, 41(3), pp. 2-13. (in Hungarian)

Feyerherm, A. E., Rice, C. L. (2002) "Emotional Intelligence and Team Performance: The Good, the Bad, and the Ugly", The International Journal of Organizational Analysis, 10(4), pp. 343-362. https://doi.org/10.1108/eb028957

George, J. M. (2000) "Emotions and Leadership: The Role of Emotional Intelligence", Human Relations, 53(8), pp. 1027-1055. https://doi.org/10.1177/0018726700538001
Gignac, G. E. (2010) "On a Nomenclature for Emotional Intelligence Research", Industrial and Organizational Psychology, 3(2), pp. 131-135.

https://doi.org/10.1111/j.1754-9434.2010.01212.x

Goldberg, L. S., Grandey, A. A. (2007) "Display rules versus display autonomy: Emotion regulation, emotional exhaustion, and task performance in a call center simulation", Journal of Occupational Health Psychology, 12(3), pp. 301-318. https://doi.org/10.1037/1076-8998.12.3.301

Goleman, D. (2001) "Emotional Intelligence: Issues in Paradigm Building", In: C. Cherniss, D. Goleman. (eds.) The Emotionally Intelligent Workplace: How to select for, measure, and improve emotional intelligence in individuals, groups and organizations, Jossey-Bass, San Francisco, CA, USA, pp. 13-26.

Goleman, D. (2004) "Érzelmi intelligencia a munkahelyen" (Emotional intelligence in the workplace), Edge 2000, Budapest, Hungary. (in Hungarian)

Goleman, D., Boyatzis, R., McKee, A. (2003) "A természetes vezető: Az érzelmi intelligencia hatalma" (Primal leadership: The power of emotional intelligence), Vince Kiadó, Budapest, Hungary. (in Hungarian)

Langhorn, S. (2004) "How emotional intelligence can improve management performance", International Journal of Contemporary Hospitality Management, 16(4), pp. 220-230. https://doi.org/10.1108/09596110410537379

Lopez-Zafra, E., Garcia-Retamero, R., Martos, M. P. B. (2012) "The relationship between transformational leadership and emotional intelligence from a gendered approach", The Psychological Record, 62(1), pp. 97-114. https://doi.org/10.1007/BF03395790

Mandell, B., Pherwani, S. (2003) "Relationship Between Emotional Intelligence and Transformational Leadership Style: A Gender Comparison", Journal of Business and Psychology, 17(3), pp. 387-404. https://doi.org/10.1023/A:1022816409059

Mayer, J. D., Caruso, D. R., Salovey, P. (1999) "Emotional intelligence meets standards for traditional intelligence", Intelligence, 27(4), pp. $267-298$ https://doi.org/10.1016/S0160-2896(99)00016-1

Mayer, J. D., Salovey, P., Caruso, D. (2000) "Models of Emotional Intelligence", In: Sternberg, R. J. (ed.) Handbook of intelligence, Cambridge University Press, Cambridge, MA, USA, pp. 396-420. https://doi.org/10.1017/CBO9780511807947.019

O'Boyle, E. H., Humphrey, R. H., Pollack, J. M., Hawver, T. H., Story, P. A. (2011) "The relation between emotional intelligence and job performance: A meta-analysis", Journal of Organizational Behavior, 32(5), pp. 788-818. https://doi.org/10.1002/job.714

Palmer, B. R., Stough, C., Harmer, R., Gignac, G. (2009) "The Genos Emotional Intelligence Inventory: A Measure Designed Specifically for Workplace Applications", In: Parker, J., Saklofske, D., Stough, C. (eds.) Assessing Emotional Intelligence: Theory, Research, and Applications, Springer, Boston, MA, USA, pp. 103-117. https://doi.org/10.1007/978-0-387-88370-0_6 
Palmer, B., Gignac, G. (in press) "The Genos Social and Emotional Competence Survey - Technical Manual", Genos International Pty Ltd., Sydney, Australia, 2019.

Pérez, J. C., Petrides, K. V., Furnham, A. (2005) "Measuring Trait Emotional Intelligence", In: Schulze, R., Roberts, R. D. (eds.) Emotional Intelligence: An International Handbook, Hogrefe \& Huber Publishers, Cambridge, MA, USA, pp. 181-201.

Rapisarda, B. A. (2002) "The Impact of Emotional Intelligence on Work Team Cohesiveness and Performance", International Journal of Organizational Analysis, 10(4), pp. 363-379.

https://doi.org/10.1108/eb028958
Sy, T., Tram, S., O’Hara, L. A. (2006) "Relation of employee and manager emotional intelligence to job satisfaction and performance", Journal of Vocational Behavior, 68(3), pp. 461-473. https://doi.org/10.1016/j.jvb.2005.10.003

Wong, C. S., Law, K. S. (2002) "The effect of leader and follower emotional intelligence on performance and attitude: An exploratory study", The Leadership Quarterly, 13(3), pp. 243-274. https://doi.org/10.1016/S1048-9843(02)00099-1 